\title{
COMMUNICATIONS
}

\author{
PARTIAL CYCLECTOMY* \\ SOME FURTHER MODIFICATIONS IN TECHNIQUE
}

BY

\author{
H. B. STALLARD \\ London
}

IN 1961 I published an account of partial cyclectomy on four patients (Stallard, 1961). From eleven more patients for whom this surgical procedure seemed justifiable I have learned certain modifications of technique which I think are helpful.

Hypotensive anaesthesia and positioning of the patient's head and eye for operation are the same as described in the original paper. It is hoped that with the site of the neoplasm uppermost the vitreous will gravitate from this. It is probable that, in rotating the eye laterally for access to a neoplasm in the ciliary body anterior to the medial rectus muscle insertion, this muscle may compress the sclera more than is the case with the other rectus muscles. When the operation is done at this site it seems a desirable precaution to do a temporary medial rectus tenotomy and to suture the muscle at the end of the operation. I am uncertain about the value of Flieringa's ring in preventing vitreous loss. I have used it in ten out of fifteen patients.

\section{Conjunctival Flap}

A generous hood flap of conjunctiva is undermined with its centre in the axis of the neoplasm, and a cut is made at each end radial with the limbus. Black silk sutures are passed through the corners of the conjunctival flap and the centre of its free edge and are clamped to the head towel. Bowman's needle is passed into the anterior chamber diametrically opposite the site of the neoplasm for the purpose of injecting sterile air at the end of the operation.

The intra-ocular pressure is much reduced by temporary tenotomy of one or even two extra-ocular muscles adjacent to the site for partial cyclectomy.

\section{Scleral Flap}

A three-sided scleral flap, the anterior edge following the curve of the limbus and the lateral cuts diverging from each end of the limbal incision (Fig. 1, overleaf) towards the equator, is commended for simplicity, ease of extension posteriorly, and possibly better security than the two flaps with one radial scleral incision over the centre of the neoplasm mentioned in my original paper.

The incisions in the sclera and limbus are made vertically and not obliquely so that their depth may be more readily assessed. The lateral radial cuts must be at least 5-6 mm. clear of the assessed margins of the neoplasm. When about two-thirds of the limbus and scleral thickness have been cut a $6 / 0$ black silk suture with a needle 


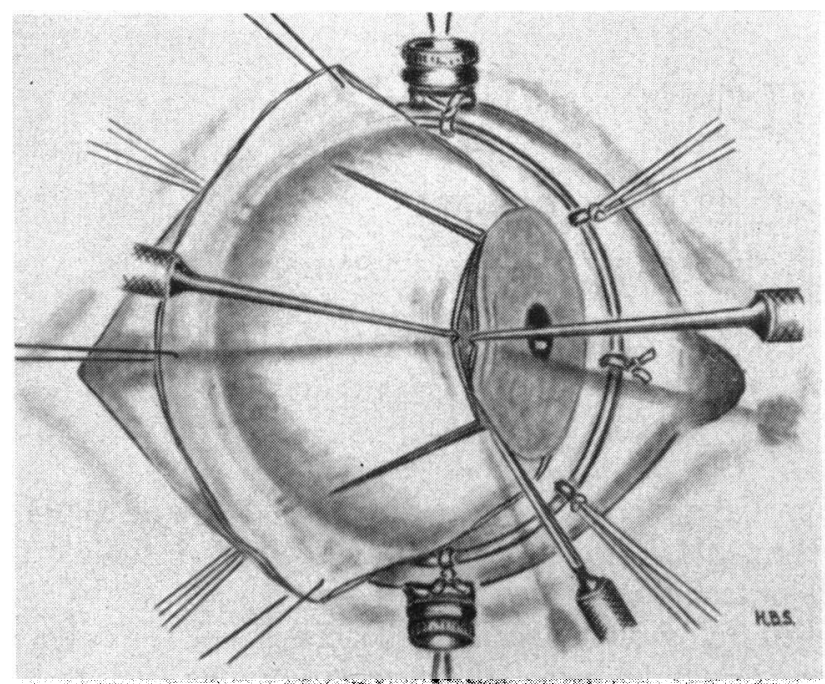

Fig. 1.-A hood conjunctival flap has been reflected. Radial cuts in the sclera and a limbal incision joining these outline the scleral flap.

at each end is inserted into each corner (Fig. 2). The posterior arm of each suture is fixed to the head towel with a heavy curved bull-dog clip, the purpose being to have a fixed point against which to pull the suture and close the scleral flap immediately after excision of the neoplasm. That part of each suture which traverses the depth of the incision between the scleral and limbal corners is pulled out into a large loop, is well moistened with saline, and is laid well clear of the field of operation. A black 6/0 suture is passed through the centre of the corneal edge of the limbal flap and a white silk suture moistened in methylene blue is passed opposite this through the scleral edge. Both these are clamped in heavy curved bull-dog clips which are used for lifting and traction of the respective flaps (Fig. 2).

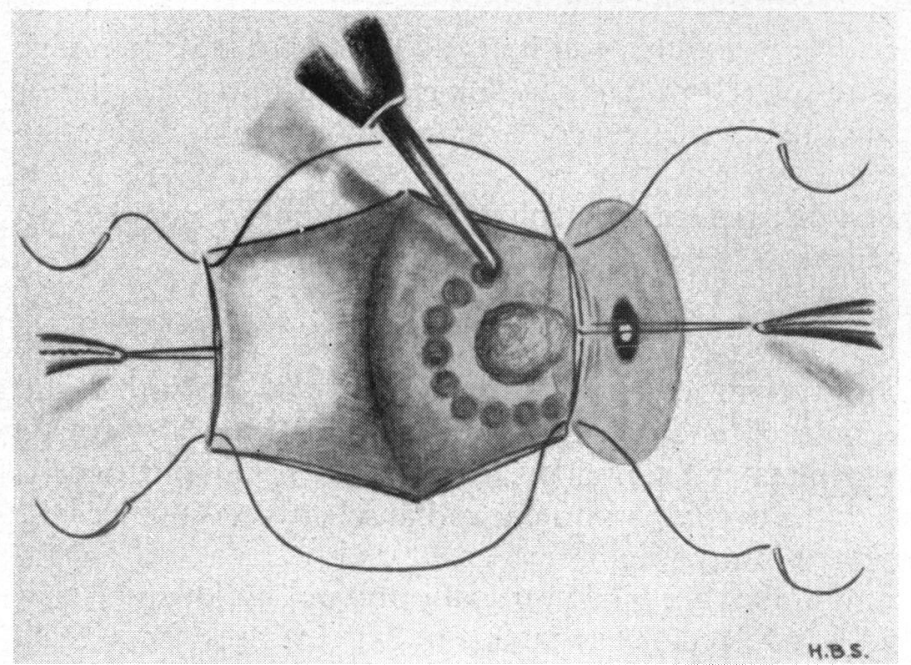

FIG. 2.-Reflection of scleral flap. The corneal flap is lifted by traction on the central suture. Corner sutures for closing the scleral flap have been inserted. The exposed ciliary body neoplasm is circumvallated with diathermy.

Louis Werner (private communication) has commented on the desirability of completing the two radial scleral incisions before the limbal. When the incision exposes in its depth part of the ciliary body, its completion is effected either by 
cautious scratching with the tip of the knife or by the introduction on the flat of Herbert's sclerotomy knife (Fig. 3). If the latter is used the sharp edge is then turned towards the surface and the cut is completed by sliding the blade gently to and fro. Herbert's knife may also be used to complete the limbal incision after the filtration angle has been entered on one side of the neoplasm. The sutures in the centre of the limbal incision, one on the corneal edge and the other on the scleral edge, are lifted by the bull-dog clips attached to them. Herbert's knife is introduced into the opening in the filtration angle with its blade on the flat and is then turned so that the cutting edge is forwards. Care is taken to keep the knife blade well forward so as not to touch the surface of the neoplasm. The blunt back of the knife may be used to separate the ciliary body from the scleral spur. The scleral flap is then gently lifted and turned posteriorly. If there is any infiltration of the sclera by the neoplasm this is separated by a diathermy needle electrocoagulation. Any suspicious areas of neoplasm in the filtration angle and the sclera are also touched with the diathermy needle. If the reflected scleral flap does not expose adequately the posterior limits of the neoplasm the radial cuts in the sclera are extended until this is so. If the neoplasm extends to within $2 \mathrm{~mm}$. of the ora serrata it is well to apply surface diathermy just behind the ora (see complications below).

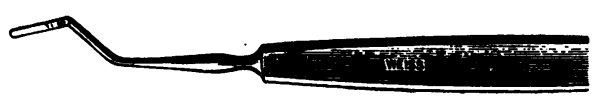

FIG. 3.-Herbert's sclerotomy knife.

\section{Diathermy Circumvallation}

No intra-ocular haemorrhage has so far occurred when penetrating diathermy through an $0.5 \mathrm{~mm}$. needle carrying $30-40 \mathrm{ma}$. is used to circumvallate the neoplasm (Fig. 2).

In one of the fifteen patients a diathermy needle $1 \mathrm{~mm}$. long was inadvertently used, and this broke the hyaloid face and embarrassed the final stages of the cyclectomy. The loops of the corner sutures in the scleral flap are now reduced so that each suture arm lies on the sclera just clear of each radial incision. One assistant holds in one hand the arms of the central corneal suture in a bull-dog clip and in his other hand the bull-dog clip holding the central scleral stitch. A second assistant holds the two corneal arms of the corner sutures.

\section{Cyclectomy}

When the neoplasm has invaded only $1-2 \mathrm{~mm}$. of the iris near its root, it is possible to spare the sphincter iridis and to make the iridectomy peripheral and at least $3 \mathrm{~mm}$. wide of the neoplasm. The bull-dog clip holding the suture through the centre of the corneal edge of the limbal incision is well lifted by one assistant so that Lang's curved iris forceps may be introduced by the surgeon into the anterior chamber without scraping the surface of the neoplasm. The forceps seize the iris $2 \mathrm{~mm}$. central to the neoplasm and withdraw it into the incision. A button-hole cut is made with fine curved anterior synechiotomy scissors immediately in front of the 
closed points of the forceps, and from this button-hole radiating cuts are made to the iris root at least $3 \mathrm{~mm}$. on each side of the neoplasm (Fig. 4).

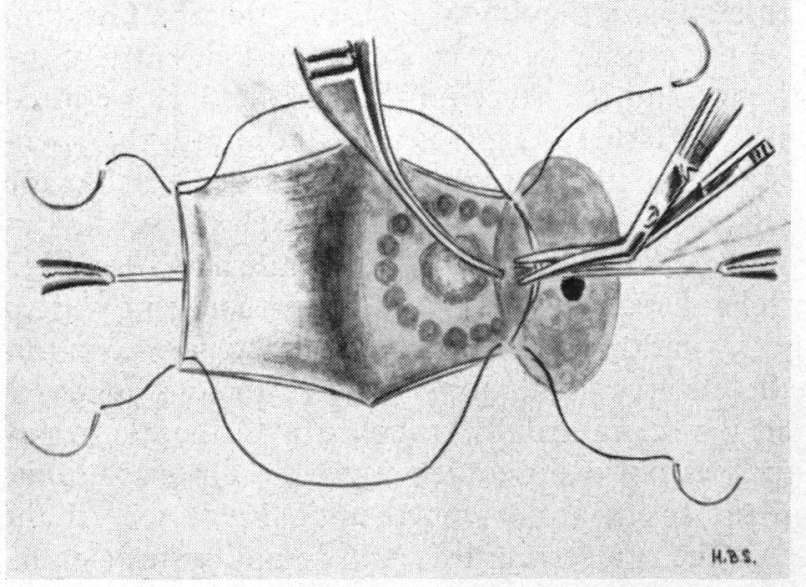

Fig. 4.-The iris, held in Lang's curved iris forceps anterior to the neoplasm, is button-holed with scissors which then make radiating cuts to the iris root on either side of the neoplasm.

The surgeon should face the exposed anterior edge of the under surface of the ciliary body and a good light should be directed from just above and behind his head. With the corneal edge retracted and the iris forceps held forward, the anterior edge of the ciliary body is in view with the suspensory ligament and the hyaloid face. It is essential to maintain the lift and slight posterior rotation of the iris forceps as the cyclectomy proceeds, and it is most desirable to cut along the diathermized area only when the tips of the scissors can be seen between the ciliary body and the hyaloid face. To do this one blade of the scissors is introduced on the flat between the ciliary body and the hyaloid face for only 2 or $3 \mathrm{~mm}$. and is turned to engage the edge, and as the snip is made the scissors is lifted (Fig. 5).

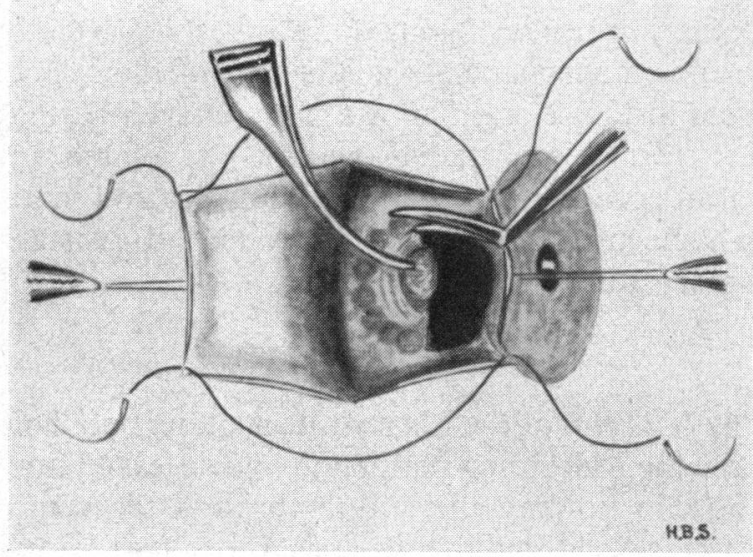

FIG. 5.-Iris forceps lift the anterior edge of the ciliary body. One blade of bluntended spring scissors is inserted between the ciliary body and the hyaloid membrane and several cuts are made in the ciliary body through the area of diathermy circumvallation.

These small cuts are made antero-posteriorly alternating on either side of the neoplasm and without haste. As the neoplasm is lifted the fibres of the suspensory ligament come into view and may be broken by a sweep with a Marten's hair brush. It is possible to keep the hyaloid intact if several small snips are made in the ciliary 
body until the excision of the neoplasm is complete. Into the defect in the ciliary body the hyaloid may bulge, but it will not break unless it is touched by an instrument or some extraneous pressure occurs.

\section{Wound Closure}

Immediately the cyclectomy is completed one assistant relaxes the traction sutures in the centre of the scleral and corneal flaps, and the other assistant who is holding the corneal arms of the corner sutures draws these taut and then swings the corneal arms over the scleral flap, a manoeuvre which helps the closure of the limbal incision. These sutures are now held securely against the head towel by the assistant's forefinger. I think this technique is preferable to drawing the sutures against a large stay-knot on the corneal arms. The central sutures in the corneal and scleral lips of the limbus incision may be crossed over and held taut (Fig. 6).

FIG. 6.-Closure of the scleral flap. Insertion of $6 / 0$ catgut sutures in the radial incisions.

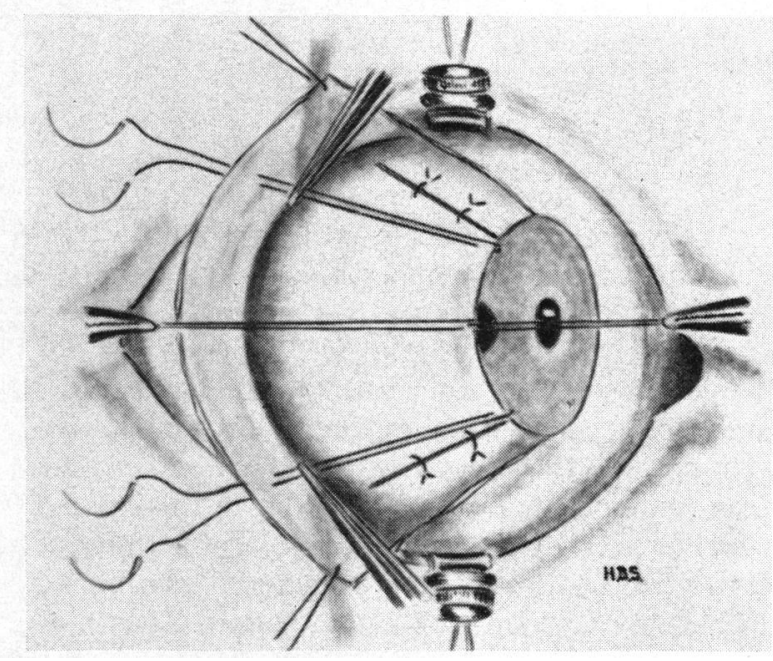

The radial cuts in the sclera are now closed with two or three interrupted sutures of $6 / 0$ catgut. The central stitch in the scleral incision, which was moistened in methylene blue, is removed and through its stained track is passed the central stitch in the corneal edge of the incision. The two arms of this suture are now carried over the sclera to be held with the corner sutures against the head towel by the assistant. The sutures which retract the conjunctival flap are now removed and the flap brought forward over the sclera.

The needles on each arm of the central suture and then those on the corner sutures are brought through the conjunctival flap about $2 \mathrm{~mm}$. from its free edge and are securely tied, first the central and then the corner sutures. The incisions at each end of the conjunctival hood flap are closed with one or two mattress sutures of 000 black silk (Fig. 7, overleaf). Sterile air is injected into the anterior chamber through the small puncture made with Bowman's needle early in the operation (Fig. 7). Atropine and an antibiotic ointment are instilled.

\section{Complications}

(1) During Operation.-The most serious complications are bleeding and vitreous loss. Up to the present time there has been no bleeding, for in all cases the ciliary body 
neoplasm has been circumvallated with diathermy $30-40 \mathrm{ma}$. for $3 \mathrm{sec}$. through a $0.5 \mathrm{~mm}$. penetrating needle.

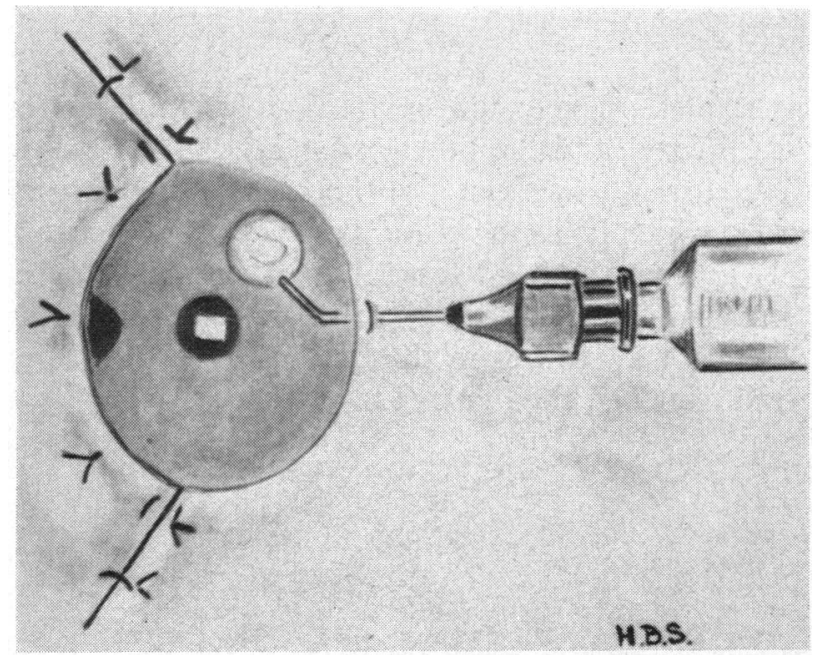

Fig. 7.-The central and corner sutures have been passed through the conjunctival hood flap $2 \mathrm{~mm}$. from its free edge and tied. Mattress sutures of 000 silk unite the lateral incisions of the conjunctival hood flap. Sterile air is injected into the anterior chamber.

Vitreous loss has occurred in three out of fifteen patients. In one there was sudden violent respiratory embarrassment and vitreous loss was about $0.12 \mathrm{ml}$., and in the other two a smaller quantity was lost. In two patients who suffered this complication the neoplasm was in front of the medial rectus insertion. In one the cause was undoubtedly a sudden violent respiratory upheaval immediately before the cyclectomy, and in the other it seemed that the tension in the medial rectus muscle with the eye rotated as far as possible to the temporal side may have caused undue pressure on the sclera immediately behind the exposed ciliary body. Moreover, in this patient it was evident that the hyaloid face had been broken by the inadvertent use of a $1 \mathrm{~mm}$. long penetrating diathermy needle. In the third patient an attempt was made to separate with an iris repositor some exudate between the ciliary body and the hyaloid face. The tip of the iris repositor was momentarily out of sight beyond the ciliary processes and probably ruptured the hyaloid.

The lesson of these mishaps is obvious: to effect diathermy circumvallation either with a blunt electrode or with a needle no longer than $0.5 \mathrm{~mm}$., and to keep the tip of the scissors between the ciliary body and the hyaloid constantly in view.

(2) After Operation.-So far there has been no instance of reactionary (secondary) intra-ocular haemorrhage. When a lens opacity has been present before operation from local pressure of the neoplasm, this has not increased after cyclectomy, nor have any other opacities appeared, and despite disruption of part of the suspensory ligament there has been no displacement of the lens in any case.

Retinal detachment occurred 9 weeks after operation when a large medullo-epithelioma which extended into the pars plana was excised. It is possible that this could have been avoided by applying prophylactic diathermy to the retina behind the ora serrata in a sector 4 to $5 \mathrm{~mm}$. wide of the neoplasm.

\section{Summary}

Certain technical improvements and precautions against complications in the operation of partial cyclectomy are discussed.

\section{REFERENCES}

STAllaRd, H. B. (1961). Brit. J. Ophthal., 45, 797.

WeRner. L. Private communication. 